\title{
Transferrin Measurement
}

National Cancer Institute

\section{Source}

National Cancer Institute. Transferrin Measurement. NCI Thesaurus. Code C82037.

The determination of the amount of transferrin present in a sample. 